\title{
Towards ICT Impact Framework: Private and Public Sectors Perspective
}

\author{
R. Gatautis, A. Medziausiene, A. Tarute, and E. Vaiciukynaite
}

\begin{abstract}
Growing ICT role and adaptation implies various attempts to understand what economic benefits ICT bring to private and public sectors. Private sector was deeply analyzes by various researchers; however ICT impact on public sector is not explored in deep. Paper analyzes ICT development preconditions as well as various perspectives towards ICT economic impact evaluation. Considering earlier research paper proposes conceptual ICT impact on private and public sectors assessment model.
\end{abstract}

Index Terms-ICT impact, impact evaluation framework, public sector, business sector.

\section{INTRODUCTION}

The evolution of information communication technologies (ICT) uptake has become popular to depict as a process involving transitions toward increasing use of ICT coupled to organizational change and sophistication which can impact organizational performance. This process should not be interpreted as a generic or deterministic process of adaptation that can be replicated across institutional contexts. Some researchers are tend to describe this process as starting from simple ICT applications (such as e-mail) and moving towards more complicated ICT applications such as e. shop, procurement, networked organizations. The most advanced stage of ICT application is considered digital ecosystems [1]. However, there are many 'environmental' elements, ranging from policy frameworks, supporting public administrations, competitiveness/collaboration frameworks, levels and quality of education, entrepreneurial culture and others, that condition the evolution of ICT adaptation as well as ICT impact.

The impact of ICT on the wide economy is expected in the short term, reductions in the relative prices of ICT products increase investment; as well as in the longer term, as the new technologies are adopted throughout the economy, new goods are developed and new modes of business organization come into use. ICT impact on productivity arises through three main channels [2]:

- Efficiencies are realized through rapid technological progress in the production of ICT goods and services in ICT producing industries. Thus, the ICT sector is a driver of productivity growth for the whole economy.

Manuscript received October 22, 2013; revised December 29, 2013. This work was supported by Lithuania Research Council and Ministry of Education and Science of the Republic of Lithuania.

The authors are with the Marketing Department, Kaunas University of Technology, Kaunas LT-44309, Lithuania (e-mail: Rimantas.Gatautis@ktu.lt; Audrone.Medziausiene@ktu.lt, Asta.Tarute.Gatautis@ktu.lt, Egle.Vaiciukynaite@ktu.lt).
- Investments in ICT provide more capital for workers which raises their productivity;

- Greater use of ICT in all sectors in the economy helps firms to increase their efficiency.

These three effects do not occur simultaneously. Investments translate into efficiency gains only after a time lag, as ICT is used to reorganize the production process. Therefore, the impact of ICT on the wide economy is expected in two waves: in the short term, reductions in the relative prices of ICT products increase investment; in the longer term, as the new technologies are adopted throughout the economy, new goods are developed and new modes of business organization come into use.

Contribution of ICT to development is mainly determined by structural change aimed at boosting the production and adoption of new and knowledge-intensive technologies. Enabling structural factors include [2], [3]:

- Flexibility of product market including light product market regulation, low entry and exit costs, and competitive environment. Competitive environment provides the necessary incentives for companies to invest, adopt innovative technologies, transfer technologies, collaborate and enhance innovation.

- Innovation systems are a key underlying factor driving productivity. The US innovation system has better linkages between different players, better quality and funding of its knowledge sector, and more favorable framework conditions. The innovation systems also play key role in supporting clusterizations and value networks/systems development.

- Entrepreneurial culture is an essential component of an efficient innovation system. To be innovative, a firm must be able to recognize market opportunities, respond innovatively and have a large knowledge base. In the context of ICT the particular attention is paid to web entrepreneurship - understanding how ICT tools helps identify and capture new opportunities within digital markets.

- Flexibility of labor market is essential in the presence of technological change. Inadequate employment legislation may hamper the capacity of firms to reorganize and experiment with the new technologies, may limit the migration of skilled labor and the flexibility in working hours. To facilitate migration between jobs, flexible labor markets should involve life-long learning solutions and ensure the upgrade of skills.

- ICT skills are crucial both to the ICT industry and to the rest of the economy. The ICT industry relies on well-educated scientists and engineers, while companies in all sectors need to implement new technologies and rely on a skilled labor force. In the last decade, the share 
of the labor force with ICT skills has steadily increased. It has been estimated that around $20 \%$ of total employment in modern economies can be classified as ICT-skilled employment. Educational and vocational training systems are hence necessary factors to successfully exploit the advantages of ICT.

- Organizational changes. Studies typically find that the greatest benefits from ICT are realized when ICT investment is combined with other organizational changes, such as new strategies, new business processes and practices, and new organizational structures. The common element among these practices is that they entail a greater degree of responsibility of individual workers regarding the content of their work and a greater proximity between management and labor. From the ICT perspective organizational changes deal with networked business/enterprises issues, virtual organizations and digital business ecosystems.

- Flexible financial markets making venture capital finance available to innovating firms, is key to an enabling innovative environment.

ICT adoption is largely faces by various facilitators and barriers. Although different studies indicate different factors the main facilitators and barriers are following [2], [4]:

Facilitators:

- Commitment and support of industry associations and governmental bodies. In fact, this is one of the strongest arguments in favor of ICT adoption.

- The possibility to exploit synergies by having access to resources from other initiatives or organizations. ICT adoption is usually supported by various funds and programs, so possibility to obtain additional support or knowledge is always driving adoption element.

- In private sector competitive pressure plays important role in ICT adoption, as companies with slow adoption risk to disappear from the market.

- In case of ICT adoption support programs ease of participation also plays crucial role in decision to obtain support for ICT adoption.

Barriers:

- Lack of awareness, often combined with mistrust regarding ICT and ICT service providers is quite a common problem between private and public organizations.

- Although ICT is characterized by decreasing prices, ICT cost is often reported as a barrier for ICT adoption. In this case the financial contribution required from the company is not always adequate.

- The lack of internal ICT as well as ICT management knowledge slows down ICT adoption. IN many cases organizations are aware of ICT adoption benefits, but having only technological solutions does not imply efficient use of ICT.

Considering these issues as preconditions for ICT adoption we will analyze deeper ICT economic impact assessment perspectives in private and public sectors.

\section{ICT IMPACT IN PRIVATE SECTOR}

Private sector is tending more quickly to adopt ICT especially considering competitive pressure in the markets. According to Manochehri, Al-Esmail and Ashrafi ICT have four main contributions to organizations [5]:

- More visibility to business enterprises;

- Provide more information to small firms;

- Allow enterprises to overcome traditional trade barriers;

- Facilitate financial transactions.

Some companies expect fast benefits from ICT adoption; however, it is important to emphasize importance of long term investments in ICT because the positive impact of ICT occurs only after a period of adoption [6]-[8]. Also it is important to note that organizations adopting ICT have to adjust their structure, make internal changes such as personnel training, or even reconsider how different processes are implemented.

Economic research has confirmed the impact of ICT on firms' productivity. A common observation is that this effect has been larger among US enterprises over the past 10-15 years than in EU enterprises. This has been a major concern of EU policy for years. In 2006,e-Business W@tch asked companies across the EU to assess the impact of ICT on their own business. The "efficiency of business processes" and "work organization" are the areas where most companies have experienced positive effects. This confirms, once again, that ICT is a key instrument to optimize linkages in the internal value chain and across enterprises.

After a thorough situation analysis of advanced economies and some newly industrialized countries Hanna suggested a pervasive impact of ICT on [9]:

- Markets - ICT is transforming global and local markets;

- Organizations - organizations focuses on their core competencies while outsourcing increasing amounts of activities and services;

- Competitive strategies - ICT-induced changes are transforming the rules of competition and giving rise to new types of competitive strategies: innovation-driven competition, time-based competition, mass customization, lean manufacturing and demand-driven, built-to-order products;

- Innovation - ICT is enabling the creation and evolution of innovation clusters, knowledge networks, and learning communities;

- Financial and other services - ICT allows establishing financial systems without first building a fully functioning financial infrastructure;

- Employment - ICT-induced changes in jobs and employment opportunities are leading to labor migration and global competition for knowledge workers, particularly in the ICT industries;

- Education - new competition, modes of operation, and forms of delivery are emerging in higher education and corporate training, including distance education, open online universities, mega and virtual universities, corporate universities and various forms of private sector participation and borderless educational services;

- Regional and spatial development - ICT revolution is likely to promote dispersal of services that can be delivered remotely and effectively;

- Poverty reduction - ICT can open up new opportunities for the poor and small enterprises. 
Consoli after analysis of various research on ICT impact proposed 4 main dimensions demonstrating ICT impact effects [10]:

- Performance;

- Growth;

- Expansion;

- New products.

Each of group consists of several dimensions, such as efficiency, productivity, product quality, etc. Studies show that investments in ICT had a considerable effect on the productivity of the labor force and on economic growth [5], [11], [13].

It is also known that ICTs make services more easily tradable and increase productivity in manufacturing enterprises [5]. A growing number of studies confirmed a positive and significant effect on productivity. In addition, other studies indicate that the productivity effect is not only significant and positive, but increasing in both sectors: private and public [13].

Matei and Savulescu found out that Lau and Tokutsu analyzed the contribution of ICT investment on economic growth in the US for 1960-1990 period, revealing that half of the economic growth in the US was due to ICT investment [14]. Authors also refer to World Bank studies on a sample of 20000 businesses in 50 developing countries, which proved that sales grow faster, productivity is higher and also employee's growth is faster in companies using ICT. Matthews supported this approach and stated that ,there is some empirical evidence that small firms employing ICT enjoy enhanced profitability and outreach and thus can better position themselves for more wholesale expansion" [15]. Interestingly ICT does not need to be considered solely as a growth driver, to a large extent it also functions as a growth supporter [16].

However, research has usually focused on direct, easy measurable effects of ICT (e.g. growth, productivity, profits etc.) while indirect effects, especially of ICT on SMEs performance, have been, in general, less studied.

\section{ICT IMPACT IN PUBLIC SECTOR}

Comparing to private sector public sector is usually described as slowly ICT adopting sector. On one hand it might be explained by slow decision process and lack of competition pressure, on other hand public sector always observe private sector learning from their experience and trying to avoid mistakes [17].

Andersen, Henriksen, Medaglia, Danziger, Sannarnes, and Enemærke investigated the impact of ICT on the public sector [18]. They noted a limited number of impacts on value distribution and orientations. There is a need to systematically develop a comprehensive taxonomy of impacts of ICT on public sector [18]. Earlier ICT impact on private sector was mainly related to eGovernment studies.

eGovernment studies often analyzes eServices development and acceptance. It is important to create electronic services that account for needs of citizens businesses, and partners [19]. Recently, e-services and eGovernment services have been debated widely in the literature [20]. Some authors categorise eService in the public sector into e-public service and eGovernment. Based on Hassan, Shehab, and Pepard e-service is defined as "the provision of service over electronic networks" [21].

eGovernment enables citizens to have access to government information, programs, services and reduces unnecessary interventions [22]. As consequence, it raises the overall efficiency and effectiveness. Thus, eGovernment relates to the provision of democracy and makes new participations forms (e.g., via the Internet) and contributes to legitimization as well [17]. ICTs enable governments to increase openness and transparency in their performance and reduce corruption [21]. However, eGovernment is strengthening the performance of government and public administration [17]. The present study refers to broad understanding of eGovernment and encompasses all aspects of government activity.

However Andersen et al. in their research identified the impacts of ICT on the public sector as four domains [18]:

- Capabilities;

- Interactions;

- Orientations;

- Value distribution.

The first group of impacts of ICT on the public sector is capabilities. "The impacts on the capabilities of a political unit assess whether ICT has an effect on the manner in which a unit deals with its environment, in an attempt to control the environmental effects on its behavior and to extract values from the environment" [18].

The second group of impacts of ICT on the public sector is interactions. The impacts on the interactions between the political unit measure how ICT affects patters of power and control, communication among units, the coordination of tasks or policies, and the cooperation among actors performing a function within the public sector" [18]. Researchers noted that it includes the relations between the public sector and citizens or business and relations among citizens' groups. The group of interactions consists of five aspects of impacts of ICT on the public sector.

The third group of impacts of ICT on the public sector is orientations. The impacts on orientation assess how ICT affects the political unit cognitive, affective, and evaluative considerations. ICT can remove human discretion (reduce corruption) from decision phases but cannot help to structure all activities in the public sector. Smith, Noorman, and Martin argued that the removal of human element in decision-making can be problematic when the outcomes are difficult to replace [17]. However, it creates new opportunities to improve decision-making and ensure greater discretion over decisions.

The forth group of impacts of ICT on the public sector is value distribution. The impacts on value distribution assess whether a political actor experiences a shift in values that is attributable to ICT [18], [19]. It is surprising that there numbers of articles which present findings related to the impact of ICT on the distribution value, especially, protection of legal rights. Bertot, Jaeger, and Grimes argue that though the atmosphere of openness that identifies and reduces corrupt behaviour can be created by ICT technologies [23]. The amount of corruption is various across countries and depends on the country, government system and culture. 
Corruption harms the whole society and affects the economy [22]. According to Iqbal and Seo corruption "is a kind habit somewhere". Iqbal and Seo analyzed the Korean cases and indicated that ICTs have positive impact in order to reduce corruption [24]. The authors suggest other developing countries to follow the learning from Korea. Andersen and others explored study confirms that eGovernment significantly reduces corruption and supports the approach that eGovernment is a successful tool in order to combat corruption [18].

It should be noted some researchers also emphasize ICT impact in innovation context in the public sector. ICT enable innovations but this is not still enough recognized. Innovation drives economic competitiveness and sustained long-term economic growth [18], [25]. Public sector innovations include new products, services, improved products / services, and new processes. Just few studies have started to analyze the innovations in the public sector. Public sector innovations include new products /services, process innovations, collaborative innovations. Study by Gonzalez, Llopis and Gasco results revealed that the most frequent innovations are collaborative in the context of local governments [26]. Moreover, innovation is driven to improve service performance in the public sector and create value [27], [28].

\section{CONCEPTUAl ICT IMPACt ASSESSMENT FramewORK FOR PUBLIC AND PRIVATE SECTORS}

As analysis of ICT impact on public and private sector demonstrates there several common areas where ICT impact in both sectors are expected. Considering various researcher perspectives we propose the following ICT impact model:

1) ICT impact in private sector is assessed through 4 dimensions:

- Performance - considering ICT impact for efficiency, effectiveness, competitiveness and intangible benefits;

- Growth - considering productivity growth, sales growth and strategic growth;

- Expansion- considering organizational expansion, communication expansion, as well as supply network expansion;

- New products- considering new products/services, product quality and customers satisfaction;

2) As well ICT impact on public sector is assessed through 4 dimensions:

- Capabilities - considering information quality, efficiency and effectiveness;

- Interactions - considering coordination with business and citizens, coordination with partners, and organizational control;

- Fostered democracy and citizens engagement considering feedback opportunities from various stakeholders, citizens engagement in policy formulation, policy development process improvements;

- Innovations - considering new products and services, improved products and services, and new processes;

The proposed framework identifies dimensions and indicators in public and private sectors regarding ICT economic impact assessment. The future research will consider different factors affecting ICT adoption (such as ICT investment, ICT knowledge, ICT knowledge improvement) and their relation to dimensions and indicators identified within the framework. The differences of these relations between different sectors, different types of companies (size, type, lifecycle) and governmental organizations (type, size) will be assessed.

\section{CONCLUSION}

Whilst there are many theoretical studies of ICT impact on different sectors, detailed comparisons between ICT impact on private and public sectors are lacking. In order to promote ICT adoption it is critical to clarify the possible impact of ICT on both sectors.

Various researches identify main impacts such as increased productivity and efficiency, economic development and growth. Moreover, these impacts could be considered as common in both sectors. Therefore it can also be stated that ICT provides opportunities for public sector to ensure better quality of service delivery, increase the efficiency, cut expenses/cost savings, lead to transparency, efficiency and effectiveness.

The proposed conceptual framework identifies 4 dimensions for ICT impact assessment in private sector as well as 4 dimensions for ICT impact assessment for public sector. It must be considered the framework was developed basing on earlier research and might have limitation in collecting required indicators.

The proposed framework is useful in association to various factors facilitating and slowing ICT adoption enabling researcher develop various hypothesis and empirically testing them in different countries, markets as sector. These hypotheses might be built on earlier theoretical or empirical observations, but considering different conditions for ICT adoptions hypotheses verification indifferent countries, markets or sectors will be different.

\section{ACKNOWLEDGMENT}

This research was funded by Lithuania Research Council and Ministry of Education and Science of the Republic of Lithuania.

\section{REFERENCES}

[1] F. Nachira. (2013). Towards a network of digital business ecosystems fostering the local development. Ecosystems. [Online]. Available: http://www.digital-ecosystems.org/doc/discussionpaper.pdf

[2] R. Gatautis and E. Vitkauskaitè, "e-Business policy support framework," Engineering Economics (Inžineriné Ekonomika), vol. 5, no. 65 , pp. $35-47,2009$.

[3] R. Gatautis, "The impact of ICT on public and private sectors in Lithuania," Engineering Economics, vol. 4, pp. 18-28, 2008

[4] M. Seppä, T. Damaskopoulos, and R. Gatautis, "Evolution of e-business policy in Europe: from technology-push to digital business ecosystems, innovation partnerships, and living labs," in Proc. the 2nd International Conference on Changes in Social and Business Environment, pp. 228-234, 2007.

[5] N. N. Manochehri, R. A. Esmail, and R. Ashrafi, "Examining the impact of information an communication technologies (ICT) on enterprise practices: A preliminary perspective from Qatar," The 
Electronic Journal on Information Systems in Developing Countries (EJISDC), vol. 51, no. 3, pp. 1-16, 2012.

[6] D. Consoli, "Literature analysis on determinant factors and the impact of ICT in SMEs," Procedia - Social and Behavioral Sciences, vol. 62, pp. 93-97, 2012.

[7] D. A. Higon, "The impact of ICT on innovation activities: Evidence for UK SMEs," International Small Business Journal, vol. 30, no. 6, pp. 684-699, 2013

[8] C. L. Nicolas and P. S. Acosta, "Analyzing ICT adoption and use effects on knowledge creation: An empirical investigation in SMEs," International Journal of Information Management, vol. 30, pp. 521-528, 2010.

[9] N. Hanna, "Why national strategies are needed for ICT-enabled development," ISG Staff Working Papers, no. 3, pp. 6-47, 2003.

[10] D. Consoli, "Literature analysis on determinant factors and the impact of ICT in SMEs," Procedia - Social and Behavioral Sciences, vol. 62, pp. 93-97, 2012.

[11] A. O. Lopez and M. E. A. Muneta, "ICT impact on competitiveness, innovation and environment," Telematics and Informatics, vol. 29, pp. 204-210, 2012

[12] K. Sabbagh, R. Friedrich, B. E. Darwiche, M. Singh, and S Ganediwalla, "Maximizing the impact of digitization," The Global Information Technology Report, pp. 121-133, 2012.

[13] T. P. Liang, J. J. You, and C. C. Liu, "A resource-based perspective on information technology and firm performance: A meta analysis," Industrial Management and Data Systems, vol. 110, no. 8, pp. 1138-1158, 2011

[14] A. Matei and C. Savulescu, "Empirical analysis of ICT, economic growth and competitiveness in the EU," in Proc. the International Conference on ICT Management (ICTM 2012), Wroclow, Poland, September 17-18, 2012

[15] P. Matthews, "ICT assimilation and SME expansion," Journal of International Development, vol. 19, pp. 817-827, 2007.

[16] B. H. Hall, F. Lotti, and J. Mairesse, "Evidence on the impact of R\&D and ICT investments on innovation and productivity in Italian firms," Economics of Innovation and New Technology, vol. 22, no. 3, pp. 300-328, 2013.

[17] T. Schuppan, "E-Government in developing countries: Experiences from sub-Saharan Africa," Government Information Quarterly, vol. 26, no. 1, pp. 118-127, 2009

[18] K. N. Andersen, H. Z. Henriksen, R. Medaglia, J. N. Danziger, M. K. Sannarnes, and M. Enemærke, "Fads and facts of e-government: A review of impacts of e-government (2003-2009)," International Journal of Public Administration, vol. 33, no. 11, pp. 564-579, 2010.

[19] P. T. Jaeger and K. M. Thompson, "E-government around the world: Lessons, challenges, and future directions," Government Information Quarterly, vol. 20, no. 4, pp. 389-394, 2003
[20] G. Goldkuhl and A. Röstlinger, "Development of public e-services-a method outline," presented at 7th Scandinavian Workshop on E-Government (SWEG-2010), 7 October 2010.

[21] H. S. Hassan, E. Shehab, and J. Peppard, "Recent advances in e-service in the public sector: State-of-the-art and future trends," Business Process Management Journal, vol. 17, no. 3, pp. 526-545, 2011.

[22] C. K. Kim, "Anti-corruption initiatives and e-government: A cross-national study,” Public Organization Review, pp. 1-12, 2013.

[23] M. L Smith, M. E. Noorman, and A. K. Martin, "Automating the public sector and organizing accountabilities," Communications of the Association for Information Systems, vol. 26, pp. 1-16, 2010.

[24] M. S. Iqbal and J. W. Seo, "E-Governance as an anti-corruption tool: Korean Cases," Journal of Korean Association for Regional Information Society, vol. 11, no. 2, pp. 51-78, 2008

[25] M. Cardona, T. Kretschmer, and T. Strobel, "ICT and productivity: Conclusions from the empirical literature," Information Economics and Policy, vol. 25, pp. 109-125, 2013.

[26] R. Gonzalez, J. Llopis, and J. Gasco, "Innovation in public services: The case of Spanish local government," Journal of Business Research, vol. 66, no. 10, pp. 2024-2033, 2013

[27] S. M. Lee, T. Hwang, and D. Choi, "Open innovation in the public sector of leading countries," Management Decision, vol. 50, no. 1, pp. $147-162,2012$

[28] R. Heeks and S. Bailur "Analyzing e-government research: Perspectives, philosophies, theories, methods, and practice," Government Information Quarterly, vol. 24, no. 2, pp. 243-265, 2007.

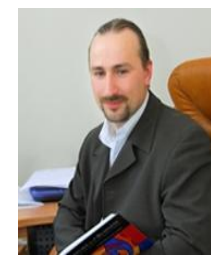

R. Gatautis was born in Kaunas, Lithuania, 1974 Rimantas holds a Ph.D. in economic sciences he received from the Kaunas University of Technology, Lithuania. His research concentrates on the IST influence on enterprise transformation in transition economies, e-business models in transition economies, socio-economic aspects of IST adaptation, IST influence on governance and democracy processes, knowledge role in value creation and knowledge driven innovations.

R. Gatautis is also member of several scientific and advisory committees responsible for evaluating national government programs in the domains of electronic business and electronic government. He served as an expert in Lithuania National Study and Science Fund, Lithuania Science Board Information Society Development Committee under Lithuania Government, Education Studies Quality Assessment Centre, National Development Agency. 